MATEC Web of Conferences 46, 01004 (2016)

DOI: $10.1051 /$ matecconf/20164601004

(C) Owned by the authors, published by EDP Sciences, 2016

\title{
Recent progress on test evidence, standardization and design of protection for exterior openings
}

\author{
Ruth Astrid Strøm
}

Securo AS, Norway

\begin{abstract}
Any opening in the exterior of structures are critical when exposed to fire. Windows and doors may be open, ventilation openings may be unprotected, wall cladding and roof tiles may allow flames or embers to enter cavities. Gaps may have developed over time and allow embers to settle in crevices or cavities in the structure. In fact, rarely does initial fire penetration occur right through cladding, sheets, insulation or solid walls. Penetration is most often related to openings, weak joints or cracks.

There is no doubt these weak points to fire spread in construction or indoor are crucial to the outcome of exterior fire exposure whether caused by wildfire or fire in outdoor trash or neighbouring buildings. Therefore, this has been addressed by authorities, standardization bodies and industry world-wide and much progress have been made during the last decade. This paper provide overview on new standards, on codes and on various pass/fail criteria set by code or classification standards. The paper describes how new designs of fire resistant ventilating facades and roofs apply dedicated cavity fire barriers and how new standard test methods helps to improve performances.

A number of different fire scenarios that elements in vented facades/constructions can be exposed to have been studied. New test standards have been developed for the last few years and are explained. Finally, this paper evaluate how different fire stop products perform in different fire scenarios and which test standards are applicable.
\end{abstract}

\section{INTRODUCTION}

Over the last decade, increasing attention has been drawn to the fire risk that openings in vented construction represent and how these should be protected.

It is crucial that fire spread in building cavities is prevented. Several different fire barriers, solid and ventilated, are available but apply for different types of fire exposures. Standard furnace test methods for exterior vents might provide limited proof of fire resistance. These tests apply the ISO 834 standard heating curve, a situation very different from the realistic worst case fire scenarios. Another concern is that temperature readings for the first 10 minutes of the fire are omitted from the tests while, according to studies done, most combustible debris ignites within 1-5 s when hit by flame [1]. For ventilating fire barriers which are open at start and then sealed upon heat exposure, this means that flames can penetrate the vent in the initial open state before it is completely sealed and spread through the building cavities.

This is an Open Access article distributed under the terms of the Creative Commons Attribution License 2.0, which permits unrestricted use, distribution, and reproduction in any medium, provided the original work is properly cited. 


\title{
MATEC Web of Conferences
}

\subsection{Pass/fail criteria and test evidence vented construction}

Exterior vents are inherently open at the time of fire starting and subject to harsh environmental exposures. An exterior fire challenges performance of vents by multiple exposures:

\author{
Embers \\ Flaming \\ Radiation \\ Sustained fire
}

of which scenarios vary from nearby building fires, wildfire, arson to auto ignition incidents. Secondary effects of exposure may be metal expansion against supporting construction, delamination and deflection of sandwich panels that create gaps for fire to pass cavity barriers etc.

\section{OVERVIEW OF EXTERIOR FIRE SCENARIOS}

\subsection{Flaming fire through window}

When window glass breaks in a fire, an immense smoke plume at $500-900^{\circ} \mathrm{C}$ is released. The plume's circumference will be flaming as it contacts oxygen in air. Part of the non-flaming hot smoke will spread into cavities where they rise as in a chimney. At first, there may not be enough air in the cavity to sustain flaming but as the buoyancy force creates substantial pressure differential more hot smoke and fresh air is drawn from all sides of the facade cavity. This may cause flaming inside the cavity or an immediate ignition of accumulated hot, unburnt smoke to a flashover. Another flaming phenomenon occurs when unburnt, hot smoke leaves the cavity from opening at the top. The unburnt gases will ignite as they get in contact with oxygen in the fresh air. This is the same principle as oil refinery torches or chimney fires as gas streams out of pipes or ducts to ignite, flare-up and sustain as a steady flame. It is assumed that this flame further increases the buoyancy force to draw even more unburnt smoke into the cavity. An assumed third effect of this condition we find no research on: The make-up air to the flaming on top of the cavity should cause an upward draft and likely extend the flame height on the outer surface as well. All this adds up to a possible explanation as to why these scenarios often escalate very fast and may explain why eaves are known as the most vulnerable part of the envelope in exterior fires.

Full scale research on the complete scenarios is lacking. Although the single effects are reported by research and observations in product and ad hoc testing the full understanding and quantification remains a hypothesis that should be investigated.

Fire through windows are most frequently applied worst credible scenario in FSE design of facades.

\subsection{Wildfire or fire in nearby structures}

Wildfire spread almost exclusively via openings, by penetration of embers or flames and to a less degree by radiated heat. The protective means are usually designed and tested to $10 \mathrm{~min}$ since a typical wildfire attach to structures last for about $3 \mathrm{~min}$ only and few more than $6 \mathrm{~min}$. Extending the burn-through times are easily achieved by increasing thickness of wood, other material, sealants or intumescents. Therefore, the groundbreaking results of wildfire protection make an invaluable base of knowledge base when designing protection against building-to-building fire spread as well.

Wildfire or fire in neighboring structures challenges facades the most. Therefore, research has led to standards for testing, fire resistive designs and test methods to verify the fire resistance or burn-through times of most parts of facades. 


\subsection{Incidental fire}

Exterior fires may develop incidentally by processes, maintenance work, play, vehicles, auto ignition and quite often in trash cans. Most of these represent slow development but are insidious as they often start at night or when unseen.

\subsection{Liquid fire}

Spilled flammable liquid fire at ground level of facade cladding may develop faster from ignition than enclosure fires in rooms. Direct flame impact from flashover by enclosure fires typically occurs after 5 min so these conditions cannot be compared.

\subsection{Flashover}

Occurs when enclosed unburnt gas/smoke ignite or get exposed to oxygen in air. It typically occurs in a room when opening a door. It may happen with cavities of facades as well when gaps develop by deflection from heat exposure or when fire fighters make access by breaking off cladding panel board.

\subsection{Direct flame impingement by hot work, pyrotechnics, lightning strikes, gas or dust explosions}

Direct flame impingement may relate to work, arson or unintentional incidents. When designing protection of façade openings even these exposure scenarios should be considered.

\section{DEVELOPMENT OF NEW CODES AND STANDARDS}

Until recently it was not considered practical to protect ventilation openings in facade by fire dampers or by automatically activated closure of fire resistance rated louvres over openings. New passive designs have been developed however, to block out fire and embers from windows, vents and gaps. Simple multiple-layer glazing provides just the required resistiveness to wildfire attack. Mesh and labyrinth type steel vents block embers and flames during this typical 3-6 min exposure.

Concerns were common globally and justified that direct flame impingement may spread during the open state of vents that seal up during first minutes of heat exposure. Work is completed in US and ongoing in Europe to develop test standards to addresses this issue.

\subsection{Europe}

National requirements within European countries vary widely. Some countries emphasize protection against wildfire, while countries at risk from "urban" type of exterior fire put resources on protection of buildings against other buildings on fire.

Work groups at CEN are currently working on two test standards for cavity barriers and air transfer grilles in Europe. The technical committee for these work groups, TC127, has instructed that testing towards sudden fire exposure should be included in both test standards.

The test standard for cavity barriers, prEN 1364-6 [2] is a continuance of the EOTA TR31 for closed cavity barriers into one single CEN test standard for both closed and open/ventilating cavity barriers. The proposed test standard is currently being prepared for enquiry.

The pass/fail criteria of the method should comply with the general requirements of EN 1363-1 [3] and the results will be valid for indoor or façade applications. The method is a small scale furnace test and functions well as a way of comparing different cavity barriers ability to prevent fire spread in 


\section{MATEC Web of Conferences}

building cavities without needing to do a considerably more expensive full scale test. For assessment of entire ventilated façade systems, however, full scale testing is necessary. There is a variety of such façade tests available [4]. Aspects on these tests will be given later.

In line with the instructions from the TC127 committee, the test standard has been prepared with an annex describing an optional test method for ventilating cavity barriers that assesses the vents ability to resist penetration of flames in the open initial state. This additional test involves a removable shield that exposes the test specimen to immediate heat exposure which simulate breaking of glass, panel delamination, cavity flashover, arson liquid fire and similar abrupt transitions to flame.

A similar optional test has been suggested in the test standard for air transfer grilles (prEN 1364-5) which may include wall vents in facades.

\subsection{USA and Australia}

A parallel to the work in Europe, test standard ASTM E2912-13 [5] was developed in USA. This is a test method for non-mechanical fire dampers in vented construction and provides an evaluation of the test specimen ability to resist passage of flames radiation and hot gases caused by sudden direct flame impingement. In short, the method functions as follows: a specimen is exposed to sudden flame impact by quickly sliding it across a test bench so that it is positioned directly above a gas burner flame. The pass criteria of integrity in ASTM E119 (standard for fire resistance [6]) is < 4 s of sustainable flame. This basically apply to the open state test as well, although the E2912 records time of failure only and do not set any criteria. The E2912-13 is an additional test for products that comply with the E119 furnace test to verify that the product meets the test criteria in open initial state as well.

SPFR explored an ad hoc test method with similar set-up for assessing open state fire resistance of exterior wall vents, air transfer grilles and linear fire barriers for concealed space and perimeter fire barrier applications [7]. Figure 1 shows thermal image and temperature diagram for such a test of a ventilating cavity barrier.

ASTM E1912-13 is by now referred to as the flame blocking test of ASTM E2886 [8] for eave vents and drafted for inclusion in test standards for more exterior fire protection product.

California State Fire Marshal are revising building codes. It has informed it will reference the new set of ASTM standards on wildfire protection in order to comply with a code requirement that opening protection shall resist the intrusion of flame and embers. The current code already require that mesh openings of vents shall be within $1.6 \mathrm{~mm}$ and $3.2 \mathrm{~mm}$ [9]. This means products and systems of limited ability to resist flame or embers will no longer be acceptable.

NFPA Standard 1144 [10] is favored by US states for protection of structures in wildfire prone areas. A draft revision appears to go the way of CSFM, i.e. referencing the new set of ASTM standards.

Australia employs much of the same fire protection methodology as the US. Standards are stricter and protection requirements given for five risk levels of exterior fire exposure, urban and wildfire types.

The Australian national science agency, CSIRO have recently led to stricter pass/fail criteria and test methods for opening protectives against flame duration, ember size and radiation levels addresses the open state before vents seal up. In general, the new criteria tend towards $2 \mathrm{~mm}$ mesh openings for protection against embers (previously $6.4 \mathrm{~mm}$ ) and no flame or $<4$ s flame duration. Radiation criteria are less changed although the critical levels and effects of radiation is still debated. The same trend applies for USA by NIST and IBHS research.

\subsection{Baltic-Nordic countries [11]}

A Baltic-Nordic edited handbook "Brandsäkra Trähus Edition 3" (in Swedish) on the design of fire protection of wooden buildings. Codes refer to the handbook which describe methods to protect openings, gaps and joints by use of fire resistance rated facades solutions, rainscreen cladding and 

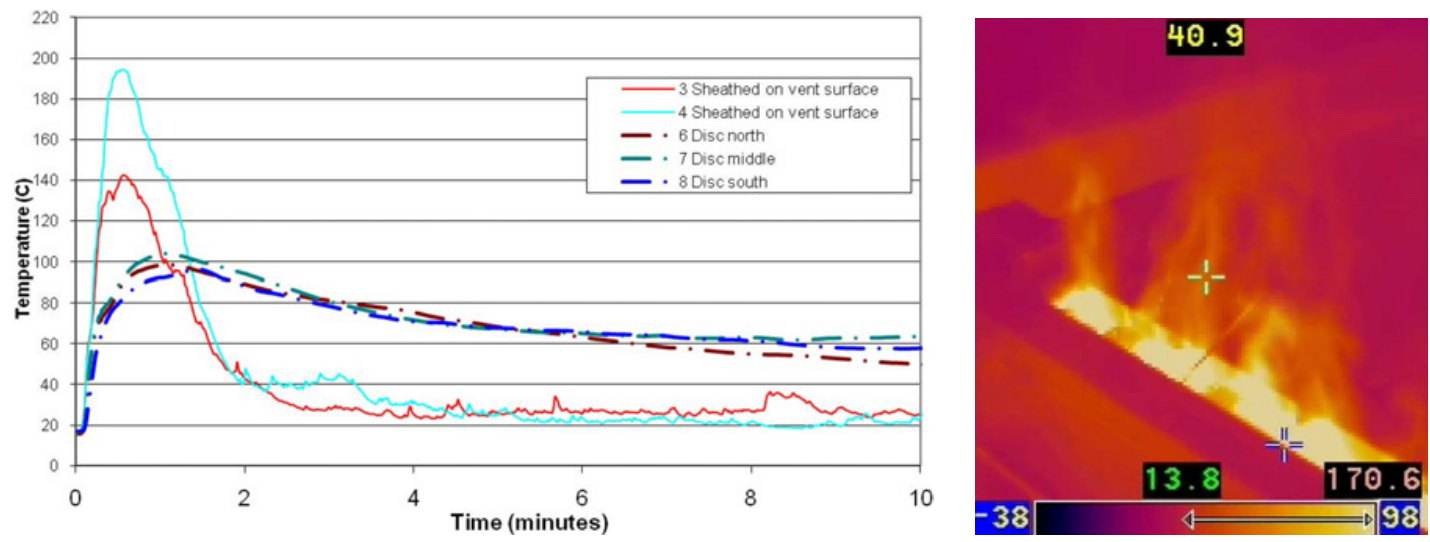

Figure 1. A cavity barrier type previously passing EN 1366-4 for EI 60 rating was used in a pilot test during development of sudden flame impingement test ASTM E2912-13. Diagram show readings of disc thermocouples to EN 1363-1 nos. 6, 7 and 8 on unexposed side. They all peaks around $100{ }^{\circ} \mathrm{C}$ at $60 \mathrm{~s}$ after direct flame exposure. For research, nondamped (sheathed) thermocouples nos. 3 and 4 were applied right above specimen and peak higher while still clearly below flame temperature during the entire open state from time of zero to about $60 \mathrm{~s}$ of flame exposure to specimen from below. Thermal images conform with readings of nondamped rather than the standard thermocouples. Note: thermal images show temperature by a color scale. Max temperature $170.6^{\circ} \mathrm{C}$, i.e. no flame (SPFR).
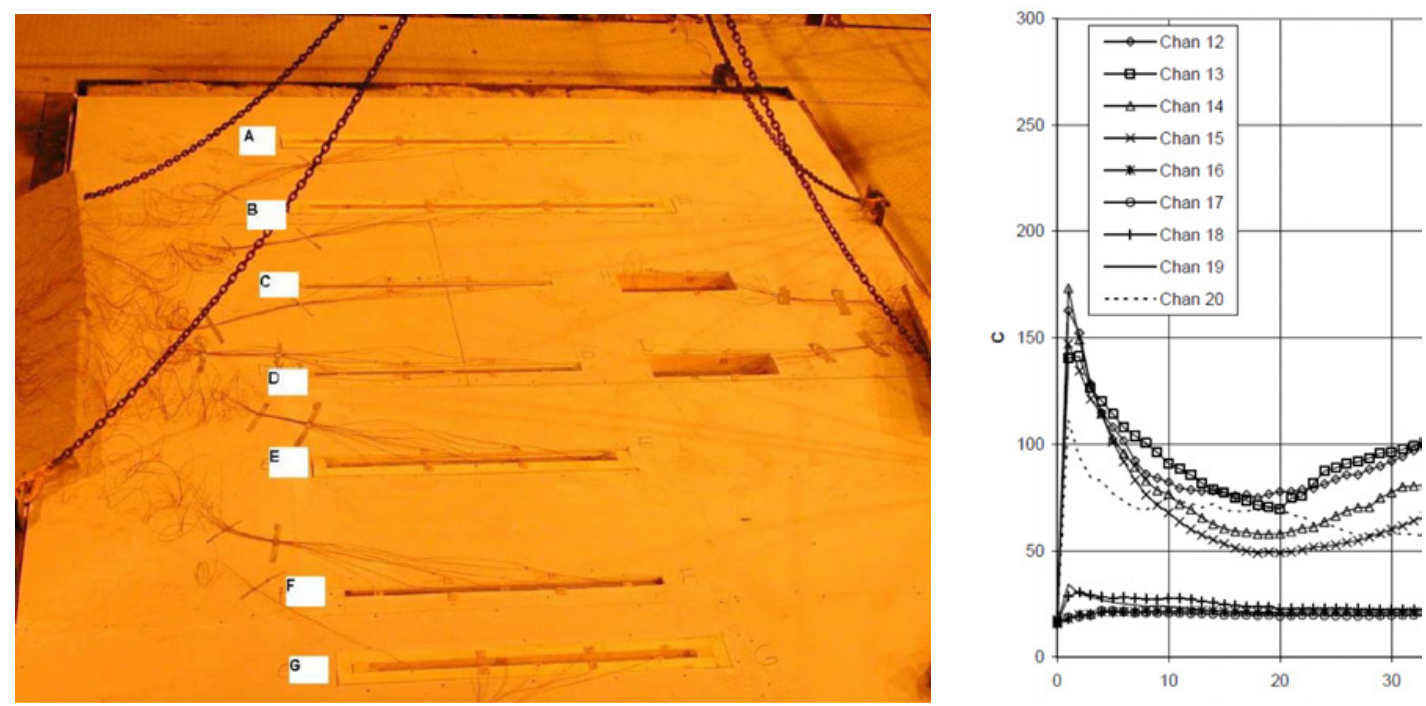

Figure 2. EI 30 cavity barrier in a EN 1366-4 horisontal furnace test of multiple specimens (SPFR)[13].

vents. The book describe fire protection of air gaps of façade cladding and points out the importance of protecting ventilated facades with cavity barriers that withstand the relevant exposures.

Such cavity vents were tested by ad hoc sudden flame impingement tests as a supplement to EN 1366-4 [12] in order to determine if acceptance criteria of EN 1363-1 are met in the open state. Figures 1 and 2 below shows test set up and time-temperature curves for these tests. These test results were considered by the working groups of ASTM and CEN along with other test evidence of UK and US types of ventilating cavity barriers. 


\section{MATEC Web of Conferences}

\subsection{Full scale façade tests}

Several methods for full-scale façade tests exists: LEPIR II, SP FIRE 105, BS 8414-1, DIN E4102-20 [14-17] and more. The advantage of such tests is that all aspects of a complex wall can be assessed from one single test.

Ad hoc façade tests demonstrate that without a fire barrier flames can spread rapidly in the cavity behind cladding regardless of the materials used in the façade and they can extend 5-10 times of original flame height as they seek oxygen for combustion [18].

Proprietary tests of façade systems to SP Fire 105 full-scale façade test proves that ventilating rainscreen cladding including wind-breaker and battens may all be combustible while still preventing fire spread. This is enabled by cavity barriers plus fire retardant paint/chemicals on the outer surface only.

One drawback with the full scale façade standards is that they do not simulate the sudden flame exposure scenarios, such as breaking of window or arson liquid fire. In other words, those tests cannot be used to fully assess the fire resistant properties of ventilating fire barriers [1]. A solution to this issue could be to add a smaller scale test standard, such as ASTM E2912-13 or CEN prEN 1364-6.

\section{CAVITY BARRIERS}

As stated above, without proper fire barrier a fire can propagate unseen in a ventilated cavity system.

The challenge with many cavity barriers is that the must serve conflicting requirements, i.e. allow air to vent the cavity and prevent flames to spread in the event of a fire [18]. Most fire stop measures available today may prevent fire spread but do not provide venting. Or, the other way around: Some ventilating cavity fire barriers provide venting but do not block penetration of all flaming scenarios. Some designs apply to specific fire exposures only. So far there is no test standard that distinguishes type of fire exposure versus type of fire barrier.

To illustrate this we looked further into a range of cavity barriers available and which fire exposures they are aimed at. This is summarized in Table 1. It should be noted that the same exposures will apply to other facade elements as well, such as wall vents or eaves vents, see the paragraph on opening protection in facades further down.

To summarize, in order to maintain adequate ventilation as well as prevent all flame penetration when exposed to fire, cavity barriers should be designed to first block flames from entering. Secondly, stop fire spread to other cavity spaces should a flashover occur in one cavity. Then, once fully sealed the cavity barriers prevent hot smoke from spreading fire to other cavity spaces during the fire resistance time of the barrier or cladding. Finally, even when the cladding itself or the barrier are burnt away this does not mean fire have spread to the next cavity space, any a remaining cavity fire may then but start exposing the next cavity barrier and its associated cladding. The latter development presumes that the fire resistive outer surface of cladding prevents fire from bypassing cavity barriers.

It should be recognized that the rationale above is deducted from cited sources only.

\section{OPENING PROTECTION IN FACADES}

While ventilating cavity barriers are part of facade construction systems, most facades incorporate some form of vents or openings for venting as well. These are not specifically addressed in this paper. These vents are however, exposed to the same exterior fires although vertically oriented. In order to protect a building by a fire safe building envelope it must resist fire uniformly, so the same or similar standards as for fire resistance rated cavity barriers exists or are being developed to apply to vent openings in facades.

Many products are developed and applied. Most are either not tested for fire resistance at all or tested in furnaces to standards for enclosure fires. Furnace testing to standard exposure however does not 
Table 1. Summary of different cavity barriers and applicable fire exposures and test methods.

\begin{tabular}{|c|c|c|}
\hline CAVITY BARRIER & FIRE EXPOSURES & TEST METHOD \\
\hline Intumescent strip & $\begin{array}{l}\text { Room fire (enclosure fire, i.e. slow } \\
\text { gradient in time, no direct flame) } \\
\text { Façade fire }\end{array}$ & $\begin{array}{l}\text { Standard furnace test and fire } \\
\text { resistance criteria. EU: } \\
\text { Comply } 5 \text { to } 30 / 60 / 120 \text { min of } \\
\text { test. prEN } 1364-6 \\
\text { or: } \\
\text { Comply full scale façade fire test, } \\
\text { SP Fire } 105 \text { or other national test. } \\
\text { Typical fire response profile } \\
\text { - El } 60 \text { min (5-60) } \\
\text { - No open state fire resistance }\end{array}$ \\
\hline $\begin{array}{l}\text { Perforated metal barrier } \\
\text { or metal sheet labyrinth }\end{array}$ & $\begin{array}{l}\text { Wildfire ember and flame attack. } \\
\text { Ad hoc rainscreen cavity fire tests. }\end{array}$ & $\begin{array}{l}\text { EU: Ad hoc full scale tests done. } \\
\text { US: ASTM E2886 Test of ember } \\
\text { and flame blocking } \\
\text { Typical fire response profile } \\
\text { - Labyrinth types pass E2886 } \\
\text { - Perforated,large holes,report- } \\
\text { ed fire spread delay 4-6 min }\end{array}$ \\
\hline $\begin{array}{l}\text { Flame quenching mesh and } \\
\text { intumescent element }\end{array}$ & $\begin{array}{l}\text { Ember attack } \\
\text { Sudden direct flame exposure } \\
\text { Room fire (enclosure fire, i.e. slow } \\
\text { gradient in time, no direct flame) } \\
\text { Façade fire }\end{array}$ & $\begin{array}{l}\text { Standard furnace test and fire } \\
\text { resistance criteria. } \\
\text { EU: Comply } 0 \text { to 30/60/120 min of } \\
\text { test. prEN } 1364-6 \text { Flame (method B) } \\
\text { or: } \\
\text { Comply full scale façade fire test, } \\
\text { SP Fire } 105 \text { or other national test. } \\
\text { US: ASTM E2912-13 + ASTM E119 } \\
\text { Typical fire response profile } \\
\text { - El } 60 \text { min (0-60) (method B) } \\
\text { - Open state fire resistance } \\
\text { - Ember resistant }\end{array}$ \\
\hline $\begin{array}{l}\text { SOLID BARRIER (Non-ventilating) } \\
\text { Wood/mineral wool/calcium } \\
\text { silicate/gypsum/steel sheet }\end{array}$ & $\begin{array}{l}\text { Room fire (enclosure fire, i.e. slow } \\
\text { gradient in time, no direct flame) } \\
\text { Façade fire }\end{array}$ & $\begin{array}{l}\text { EU: } \\
\text { prEN 1364-6 (cavity barrier test) } \\
\text { Typical fire response profile } \\
\text { - EI } 30 \text { min (expected) } \\
\text { Assumed to resist ember attacks } \\
\text { and direct flame without testing. }\end{array}$ \\
\hline
\end{tabular}




\section{MATEC Web of Conferences}

require failure of integrity and insulation to be recorded during first $5 \mathrm{~min}$ and the exposure in this period simulate a slow and uniform build-up of a smoke layer. The new standards for exterior vents addresses this by recording failures from time of 0 to $5 \mathrm{~min}$ under realistically simulated exterior exposures and include the open state before the vents are sealed or closed. The standards require a standard furnace enclosure fire test to be passed as well, for rest of the fire rated time.

Using for example ASTM E2886 with ASTM E2912 and ASTM E119 one can have fire rated vents listed for exterior openings in facades of type gable vents, foundation vents, eave vents, wall vents. Such listing verify resistance against embers, flaming and sustained fire from time of zero to $10 \mathrm{~min}, 30 \mathrm{~min}$, $60 \mathrm{~min}$ or to $2 \mathrm{~h}$ or more.

\section{CONCLUSION}

New standards are available to verify fire resistance performance of vents for protection of openings or ventilated wall cavities in facades and others are being developed. The small scale test methods were evaluated to be trustworthy with respect to replicating credible exterior fire exposures. Exterior fires are different from enclosure fires by not establishing a hot smoke layer or ventilation controlled fire while presenting several unique fire ignition and spread modes. Wildfires and structures fires as well as various incidental fires scenarios are covered.

The published set of ASTM standards involves tests of ember blocking and direct flame blocking as well as of integrity and insulation at sustained fire. The pass/fail criteria of the tests apply to the open state before vents become fully sealed as well as sustained fire during the sealed state. In the open state the exposures are characterized primarily by embers and flaming.

At CEN two standards are being developed; for cavity barriers and air transfer grilles respectively. As at ASTM, CEN aims at covering vents to protect exterior and interior openings in vented construction. The test methods however, are set up differently. ASTM apply fuel-controlled exposures while CEN apply standard furnace tests. Depending on expected service of the test specimen the CEN task group propose to alter the installation of cavity barrier specimens to simulate a sudden flaming condition. Thereby it shall meet the instruction to record any failure of fire penetration during the open state. The CEN tests are not planned to incorporate ember blocking test for exterior vents.

Not all cavity fire barriers in facades are likely to be exposed to all identified credible scenarios. It is found purposeful that no single test should verify all scenarios. This is in accordance with published ASTM standards and intention of CEN. It allows for designs and products to fit specific applications and the exposure to comply with the relevant national regulation.

\section{References}

[1] Jensen, G., "Fire spread modes and performance of fire stops in vented façade constructions overview and standardization of test methods", MATEC Web of Conferences, 9, 02002, $1^{\text {st }}$ International Seminar for Fire Safety of Facades. Paris, France, November 14-15, 2013.

[2] prEN 1364-6, Fire resistance tests for non-loadbearing elements - Part 6: Cavity Barriers.

[3] EN 1363-1:1999, Fire resistance tests. General requirements.

[4] Smolka, Miroslav et al, "Semi-natural test methods to evaluate fire safety of wall claddings". MATEC Web of Conferences, 9, 02002, $1^{\text {st }}$ International Seminar for Fire Safety of Facades, Paris, France, November 14-15, 2013.

[5] ASTM E2912-13 Standard Test Method for Fire Test of Non-Mechanical Fire Dampers Used in Vented Construction.

[6] ASTM E119. Standard Test Methods for Fire Tests of Building Construction and Materials.

[7] Test report NBL A10109 dated 2010-10-21 from SINTEF NBL. Ad hoc test of fire resistance during the open state of exposure to fire. 
$2^{\text {nd }}$ International Seminar for Fire Safety of Facades, Lund (Sweden), 2016

[8] ASTM E2886. Standard Test Method for Evaluating the Ability of Exterior Vents to Resist the Entry of Embers and Direct Flame Impingement.

[9] 2010 California Building Code, Title 24, Part 2 (First Printing), Includes Errata/Supplement through July 1, 2012. Chapter 7A - Materials and Construction Methods for Exterior Wildfire Exposure, Section 706A Vents.

[10] NFPA 1144: Standard for Reducing Structure Ignition Hazards from Wildland Fire.

[11] Östman, B. et al, "Brandsäkra trähus. Version 3” p. 125-130. AB Stjärntryck, 2012.

[12] EN 1366-4:2006+A1:2010, Fire Resistance Tests for Service Installations. Linear Joint Seals.

[13] Test report 103011.11 dated 2009-03-27 from SINTEF NBL as according to NS-EN 1366-4:2006.

[14] LEPIR II. Test method for fire spread, 1970.

[15] SP FIRE 105 Issue 5. Large scale testing of façade systems. SP Boras, Sweden, 1994.

[16] BS 8414-1 Fire performance of external cladding systems. Test methods for non-loadbearing external cladding systems applied to the face of building. BSI, 2002.

[17] DIN E 4102-20 Brand verhalten von Baustoffen und Buteilen, Teil 20: Besonderer Nachweis für das Brandverhalten von Aussenwandbekleidungen. DIN 2009.

[18] Colwell, S. and Baker, T. "Fire exposure to external thermal insulation for walls of multistory buildings. Third edition" p. 5-6 and 14-15, BRE Trust, Garston, Watford, 2013. 